\title{
Discussion on the Relationship between Exam- oriented Education and Quality-oriented Education
}

\author{
Rongsan CHEN, Min ZOU \\ School of Mathematics and Physics, China University of Geosciences (Wuhan) \\ Wuhan, Hubei, 430074
}

\begin{abstract}
Exam-oriented education and quality-oriented education are quite different. For example, exam-oriented education has a long history, and can realize the maximum justice, while the quality-oriented education is more beneficial to the healthy growth of students. Within a short period of time, exam-oriented education cannot be fully replaced by qualityoriented education. We should correctly understand the relationship between exam-oriented education and qualityoriented education. That is, it is not an either-or thing, the two modes should be organically combined and mutually supplemented. We should constantly perfect and reform the education model so as to establish the education system suitable for our national conditions.
\end{abstract}

Keywords-Exam-oriented education; Quality-oriented education

\section{INTRODUCTION}

It is written in Cihai that, "quality refers to the original characteristics and original foundation of a person or things in certain aspects. In psychology, it refers to the congenital anatomical physiology characteristics of people, which mainly include the characteristics of sense organs and nervous system, and it is the physiological condition of people's mental development, but it cannot decide the psychological contents and development level of people. Psychologically, it refers to the congenital anatomical physiology characteristics, which mainly include the characteristics of sensory organ and nervous system, and it is the physiological conditions for people's psychological development, but it cannot decide people's psychological contents and development level." Chinese examoriented education is originated from the imperial examination system that was implemented since Sui and Tang dynasties, and then evolved into the current kinds of examination systems. Exam-oriented education refers to the education mode that is emphasized on measuring student level with examination scores, and its objective is to select the minority from the majority and then send them to a higher level of school; it corresponds to quality-oriented education. Quality-oriented education refers to the education mode that regards the improvement of the educatees' quality in all aspects as the objective. It values people's ideological and ethical standards, capacity cultivation, personality development, fitness and psychological health education [1]. Since the establishment of the New China, especially since the reform and opening-up, the Party Central Committee has regarded the improvement of

About the author: Rongsan CHEN (1979-), male, born in Yingshan, Hubei, doctor, and associate professor. E_mail: rchen@cug.edu.cn. Phone No. 15071129186. whole nation quality as the essential task that concerns the overall situation of socialism modernization construction.

About the author: Rongsan CHEN (1979-), male, born in Yingshan, Hubei, doctor, and associate professor. E_mail: rchen@cug.edu.cn. Phone No.: 15071129186.

In May, 1985, Comrade Xiaoping DENG pointed out during the First National Education Work Conference since the reform and opening-up that: "The strength of our national power and the capacity for future economic growth will increasingly depend on the quality of labor workers as well as the quantity and quality of intellectuals." In the Decision of CPC Central Committee about Education System Reform that is published in the same year, it is clearly pointed out that: "In the entire education system reform process, it is requested to bear in mind that the essential objective of reform is to improve national quality, create more talents and better talents." This the original source of thought for quality-oriented education. Comrade Zemin JIANG put forward in the Report of the Sixteenth National Congress of the Communist Party of China that: "We should encourage innovation in education, deepen its reform, optimize its structure, allocate its resources rationally, raise its quality and management levels and promote qualityoriented education to cultivate hundreds of millions of highquality workers, tens of millions of specialized personnel and a great number of top-notch innovative personnel." As for the concept of "exam-oriented education" and "quality-oriented education", all of them belong to "neutral" words, and shouldn't be simply evaluated with "right" or "wrong". [2] Qualityoriented education emphasizes on comprehensive capacity, and exam-oriented education emphasizes on the ability of taking examinations, and all of them have different emphases, but no essential conflicts. Exam-oriented education and qualityoriented education are two different education modes, and all of them are based on transmitting cultural knowledge and cultivating students' capacity. Exam-oriented education has played an irreplaceable role in the long-term talent cultivation process of our country, but it has been found to have one disadvantage over the years. People expect children to accept quality-oriented education, but exam-oriented education is implemented in the current period. It is requested to correctly recognize the relationship between exam-oriented education and quality-oriented education as well as the advantages and disadvantages of two education modes, make them mutually supplement, constantly make perfection and reform, and establish the education system suitable for our country's national conditions. 


\section{DIFFERENCE BETWEEN QUALITY-ORIENTED EDUCATION} AND EXAM-ORIENTED EDUCATION

From the perspective of the meaning of words, examoriented education and quality-oriented education are not antonyms, and these two concepts are also not mutually contradictory. The difference between quality-oriented education and exam-oriented education is expressed as follows:

(1)Quality-oriented education regards the cultivation of comprehensively developed people as the guiding concept, emphasizes on cultivating and developing the quality of students in all aspects, and realizes all around development of moral, intellectual, physical, art and labor of students; Examoriented education regards the selection of people as the guiding concept, and emphasizes on the enrollment rate.

(2)Quality-oriented education emphasizes on cultivating students' capacity and the quality. The objective of qualityoriented education is to cultivate multi-layer and all-around talents, and emphasize on the comprehensive development of students. Exam-oriented education emphasizes on knowledge, and regards scores as the standard to measure education quality. Exam-oriented education mostly meets the demands for entering a higher school, and neglects the cultivation of students in other aspects, which has resulted in the students cultivated by exam-oriented education failing to adapt to the society.

(3)Quality-oriented education can make students sufficiently play the dominant role, adhere to start from the actual situation of students, respect students' personality, implement step by step, teach students in accordance of their ability, and actively create education conditions to develop students' personality. Exam-oriented education neglects the students' dominant role, while exam-oriented education is aimed to improve the enrollment rate; it only emphasizes on scores, and neglects students' initiative and creativity, without considering students' individual difference and personal characteristics, so students' characteristic specialty and intelligence are hard to be developed.

(4)Quality-oriented education pays equal attention to the similarity and personality, and pays extra attention to promoting students' comprehensive coordinated development. Exam-oriented education merely emphasizes on people's similarity, and neglects people's personality and personality development. Quality-oriented education is oriented to all students, and everyone can do their best, while exam-oriented education merely emphasizes on top students and enrolled objects; it advocates strict selection and elimination, and all of these are for the sake of the enrollment rate.

\section{THE NECESSITY FOR THE EXISTENCE OF EXAM- ORIENTED EDUCATION IN THE CURRENT PERIOD}

As the name suggests, exam-oriented education is the education for the purpose of examination. Examination system cannot improve students' overall quality, and is not based on students; long-term examination system practice has indicated that examination system has damaged students' physical and psychological health to some extent, and is bad for students' personality development, and will often cause the occurrence of hurting students' self-esteem and strike students' confidence. Although exam-oriented education has many disadvantages, it has become a common consensus that exam-oriented education should be transmitted to quality-oriented education.

People commonly hate exam-oriented education, but there are nothing changes in exam-oriented education, instead, it is further intensified. In my humble opinion, all people from the government leaders to common citizens know that examoriented education has destroyed the physical and psychological health of the next generation, and they are consistently disgusted with exam-oriented education, so the issue of exam-oriented education is not an issue of backward concept cognition. The school district housing brought by exam-oriented education has largely increased the housing price. Besides, exam-oriented education has also brought school selection issues; since qualified teaching resources are limited, people gathered together at famous schools, and don't want to lose at the starting line.

Although exam-oriented education has many disadvantages, the current exam-oriented education, especially college entrance examination is undoubtedly the fairest examination in the world, and it is the only approach for impoverished students to jump out of the agricultural background. . In case of totally repudiating exam-oriented education, the approach is unrealistic and wrong. The existing exam-oriented education is a kind of relatively matured education system; reform is a gradually varied innovation process; haste does not bring success. It is impossible to replace it within a short time; examoriented education is also implemented in Korea, Japan and other countries [1].

Currently, scores are still an important evaluation basis for evaluating whether a student is excellent, and the enrollment rate is also an important evaluation standard for evaluating whether a school is good or not. Before releasing a better talent selection standard, exam-oriented education will exist within a relatively long time. Exam-oriented education lasts from the primary school to the entrance examination of doctor, and in the progressive learning process, scores are constantly eliminating people, people with high scores can pursue future study, while people with low scores can only choose to be employed, so people with high scores can bring confidence to students and parents to some extent, and this has also brought a promising future to students. Schools with higher enrollment rate will form a good reputation in the society, and the qualified students and teachers will be further integrated, so they can gain big support from the local government and the school will become better and better. All the local governments spare no effort to create famous schools, and artificially divide schools into common schools and key schools, and the basis for entering common schools and key schools is the score, which has divided students into various grades and ranks. Currently, during the nine-year compulsory education phase, the principle of neighborhood school district enrollment as well as the relevant measures for striking school selection will be implemented, and this has basically eliminated the standard to enter a good or bad school with scores, and $100 \%$ students can have equal opportunities to complete the study at primary schools and junior high schools. Since the current compulsory education of our country is only restricted to junior high school 
and there are limited education resources above senior high school, not everyone has the opportunity to enter high school, which shall still be selected as per scores. On the basis of the national conditions, the current moral level and legal system level in the entire society are limited, and it is difficult to find a fairer and better selection mode than examinations. Examination can realize justice maximization, and it is also the selection mode that can be accepted by most people of our country. Some colleges try to adopt college entrance exam autonomous enrolment, but it is found to have many corruptive issues, and there is a big question about the fairness of autonomous enrolment. Since our selection mode cannot be separated from examination, examination cannot be separated from exam-oriented education. Thus, the current exam-oriented education in our country has the soil for its survival and the demands for long-term existence. Most people think that, exam-oriented education is a kind of unique education in China; it seems that Chinese students are spending each day living a life of three points and one line from classrooms and dining hall to the dormitory, but American students are just learning while playing. Actually, the so-called haply knowledge learning is only oriented to students studying at public schools and from American bottom-layer families with limited family incomes; students from upper class will go to exclusive schools, with huge pressure, and they still require examination for all periods of learning in America, but the only difference is that they merely regard scores as a reference, while we regard scores as the whole [3]. In 2011, Wall Street Journal investigated about 20,000 readers, and the result showed that, above $62.5 \%$ readers thought that strict eastern education is more beneficial to students' growth than the loose western education.

\section{EXAM-ORIENTED EDUCATION AND QUALITY-ORIENTED EDUCATION SHOULD BE ORGANICALLY COMBINED}

MaoTanchang Middle School of Anhui is known as the biggest college machine in Asia and the hell to heaven. The teaching mode provided by MaoTanchang Middle School has anti-education and anti-humanity features, and the characteristics include treating students as learning machine, strictly controlling students' thoughts, squeezing students' time, publicizing examination first and scores supreme, and advocating the abandon of everything irrelevant to examination and scores. Just because of this, they are regarded as the "blood and sweat school" and Foxconn of the educational circles However, there is no doubt that most students from MaoTanchang Middle School are from rural areas, and college entrance examination provides them an opportunity to study hard and change the fate of their family with high scores. Most people think that there is nothing good about the exam-oriented education, for they think that students are way too rigid and lack in creativity under exam-oriented education. Actually, the existing research results have proven that: Strict and even bold education won't kill creativity; on the contrary, the knowledge accumulated through exam-oriented education can promote the advanced occurrence of creativity [4]. Professor Weisberg studied Edison, Picasso and other creative talents, and the result showed that all of them studied and worked hard and down-to-earth, and progressively, and accumulated certain quantity of knowledge to gain success. Innovation capacity is built on the basis of the currently accumulated basic knowledge and thinking methods, while in order to let students efficiently acquire such knowledge and methods, strict education is no doubt the best approach. Of course, this shouldn't be too strict, which will cause extreme education. After Ming and Qing Dynasties, imperial examination system was gradually rigidified, and lost the initial effect a long time ago, and stepped into the extreme of eight-legged essay, with the emphasis on formalism, and less on the practical value, which was finally abolished at the late Qing Dynasty. Education should also keep up with the trend of the era, advance with the times, constantly reform and innovate, and cultivate the talent required for the era, to better serve the entire society [5].

We should correctly recognize exam-oriented education and quality-oriented education, conduct timely education reform, constantly perfect the education system, largely exert people's potential, encourage colleges to the "front task" of enrollment, implement autonomous enrolment, conduct comprehensive evaluation, and diversified enrollment [6], build the social atmosphere that can recognize all kinds of qualified talents, and abandon the thought of scores are everything. Firstly, the teaching mode should be transformed from examoriented education towards quality-oriented education; besides, it is requested to abandon duck-stuffing teaching, sufficiently exert the subjective initiative of students, and then change the thought of I should learn from I want to learn, and teachers should transform their identity from a manager to a server, and use modernized teaching equipment and teaching methods, to improve classroom efficiency, seek efficiency within $45 \mathrm{~min}$, and complete the teaching task in class, and leave lots of spare time for students to rest after class. Adopt the combination of school education and family education, adopt guided education, be patient with students, combine textbook knowledge and social practice, and make students experience the sense of satisfaction and achievement during the learning process. Secondly, establish reasonable examination system, and abandon the approach of using examination to determine a person's life. Vigorously develop vocational education, and provide more roads for students to become a useful person. Senior high school entrance examination and college entrance examination can adopt the average score of several examinations or the highest score, so that students won't regret their entire life because of one examination fault. There should be few examination contents or the make-up examination of rote memorization stuff, instead, it is requested to check examine students' comprehensive capacity. Thirdly, sound and reasonable student evaluation system. Don't evaluate students with sores, and the evaluation contents shouldn't merely emphasize on a result measured with scores, instead, the emphasis should be on the development process of students. Such progress includes students' learning objective, learning attitude, classroom performance, work quality, behavior habits, and class hour practice. In other words, as for the evaluation of students, we emphasize more on evaluating the learning process, rather than evaluating the final learning result.

Exam-oriented education and quality-oriented education are not mutually contradictory, instead, they are complementary, and all of them are indispensable parts of students' comprehensive development. Exam-oriented education 
emphasizes on the learning and mastering of basic knowledge theories, while quality-oriented education emphasizes on the cultivation of comprehensive capacity. Only when solid basic theoretical knowledge is mastered can the comprehensive capacity be further cultivated; without basic knowledge, there is no comprehensive capacity. Quality-oriented education can flexibly apply the knowledge learned via exam-oriented education. The interdependent relationship between the two has provided unlimited possibilities for the transformation from exam-oriented education towards quality-oriented education, and while implementing quality-oriented education, we should emphasize on the learning of basic knowledge, and while implementing exam-oriented education, we shouldn't forget the cultivation of students' capacity; the final objective of these two types of education is to make students learn more knowledge and improve their capacity in al aspects.

\section{SUMMARY}

Exam-oriented education and quality-oriented education are dialectical unity. Exam-oriented education has certain disadvantages, but there is no doubt that it is the fairest examination with the highest recognition degree in China, and has played an extremely important role in selecting all kinds of talents in our country, and exam-oriented education is constantly making perfection in the transformation process towards quality-oriented education. We should treat examoriented education and quality-oriented education with the opinion of every coin has two sides, and both of them have advantages and disadvantages; education must be suitable for the national conditions of the country, and we should take the essence and discard the dregs as per the national conditions of our country, and then develop the education that is suitable for our national conditions.

It takes ten years to grow trees, but a hundred to cultivate people; we should guard against arrogance, constantly perfect our existing exam-oriented education system, and realize the transformation from exam-oriented education towards qualityoriented education as soon as possible.

\section{REFERENCES}

[1] Zhenfeng ZHANG. Discussion about the Relationship between Qualityoriented Education and Exam-oriented Education[J]. Teaching and Management, 2100(18): 8-9.

[2] He CHEN, Sen LIN. Recognition about "Exam-oriented Education" and "Quality-oriented Education"[J]. Social Science Front, 2011(12): 264265.

[3] Hong YIN. Is the Franchise School in America a Success or Failure?[J]. Asia-Pacific Education, 2016(4): 213-213.

[4] Dongping YANG. MaoTanchang Middle School is understandable, but must be opposed. Guangming Education, http://edu.gmw.cn/201606/08/content_20472883.htm.

[5] Wei SUN, Yu YU. Exam-oriented Education and Quality-oriented Education Are Not Incompatible[J]. Journal of the Chinese Society of Education, 2016(5): 23-25.

[6] Weiguo ZHU. Key of College Entrance Examination Reform: Colleges to the "Front Task" of Enrollment[J]. Yuejiang Academic Journal, 2013(6): 23-26. 